\title{
Exposure to indoor PM10 and volatile organic compounds and its association with respiratory health among preschool children from urban and rural areas in Selangor
}

\begin{abstract}
Epidemiological studies have provided evidence that indoor exposure to particulate matter (PM10) and Volatile Organic Compounds (VOCs) may decrease lung function among children. In this study, 96 respondents from both urban and rural areas were selected. Personal and socio-demographic background, and other related information were collected from standardized questionnaire adopted from the American Thoracic Society. Personal air sampling pumps and PbbRAE Portable VOC Monitor were used to measure indoor PM10 and VOCs in the respondentsô houses. Lung function was measured using Chest Graph Spirometry. Results revealed that indoor PM10 level at home is higher in the urban area with mean $(76.61 \pm 17.53 \varepsilon \mathrm{g} / \mathrm{m} 3)$ compared to the rural area $(48.37 \pm 8.33 \mathrm{\varepsilon g} / \mathrm{m} 3)(\mathrm{p}<0.001)$. Indoor concentration of VOC indicate a significant difference $(\mathrm{p}<0.001)$ between urban $0.083 \mathrm{ppm}$ and rural area $0.035 \mathrm{ppm}$. Lung function; FVC \% and FEV1 \% were significantly higher in the rural area compared to the urban area $(\mathrm{p}<0.001)$. The prevalence of an abnormal of FVC \% was $75 \%$ among the urban group and $37.5 \%$ among the rural group. An abnormal FEV1 \% was found in $75 \%$ and $33.3 \%$ of respondents in the urban and rural groups respectively. Respiratory symptoms which include cough $(\mathrm{p}<0.001)$, phlegm $(\mathrm{p}<$ $0.001)$ and wheezing $(\mathrm{p}<0.001)$ were significantly higher among children in the urban area compared to those in the rural area. There was significant association between PM10 concentration with cough $(\mathrm{p}<0.033)$ and chest tightness $(\mathrm{p}<0.022)$. However, there was no significant association between respiratory symptoms and VOCs concentration. PM10 does affect lung function and is associated with increased respiratory symptoms among studied population.
\end{abstract}

Keyword: Children; Lung function; PM10; VOCs; Respiratory symptoms 